\title{
ANALISIS EFISIENSI PENGGUNAAN FAKTOR-FAKTOR PRODUKSI \\ USAHATANI PADI SAWAH DI LAHAN RAWA PASANG SURUT \\ DESA SUNGAI KAKAP KECAMATAN SUNGAI KAKAP KABUPATEN KUBU RAYA
}

\author{
HERLINA 1), ERLINDA YURISINTHAE ${ }^{2)}$, SUTARMAN GAFUR ${ }^{2)}$ \\ 1) Mahasiswa Magister Agribisnis Fakultas Pertanian \\ Universitas Tanjungpura Pontianak \\ 2) Dosen Pembimbing, Staf Pengajar Program Studi Magister Agribisnis \\ Fakultas Pertanian Universitas Tanjungpura \\ Email : Herlina_distan@yahoo.com
}

\begin{abstract}
Herlina, Analysis Of Efficiency Use Of Production Factors Of Rice Farming In Tidal Swamp Land Sungai Kakap Village, Sungai Kakap Subdistrict, Kubu Raya Regency, under the guidance of Dr. Ir. Erlinda Yurisinthae, MP as the First Supervisor and Ir. Sutarman Gafur, M.Sc, Ph.D as the Second Supervisor.

This research objectives to analyze the effect of production factors are land area, number of seeds, Urea fertilizer, NPK fertilizer, KCl fertilizer, herbicides, insecticides, fungicides and manpower to rice production and to analyze efficiency of production factors to the rice farming in tidal swamp land Sungai Kakap Village, Sungai Kakap Subdistrict, Kubu Raya Regency. The analytical method used in this research is survey method. The location was chosen intentionally in Sungai Kakap Village, Sungai Kakap Subdistrict, Kubu Raya Regency becouse this area is the center of producing rice in the Sungai Kakap Subdistrict, which consist of four orchards are Nirwana, Merpati, Merak, dan Garuda. The research sample of 35 farmers. This research used the data analysis with the Cobb Douglass Production Function and Efficiency.

The result showed that factors are land area, NPK fertilizer, KCl fertilizer, herbicides and manpower partially significantly influence the production in the rice farming activities while the number of seeds, Urea fertilizer, insecticides and fungicides partially does not significantly affect the production in the rice farming. The use of production factors in the rice farming in Tidal Swamp Land Sungai Kakap Village, Sungai Kakap Subdistrict, Kubu Raya Regency in the form of land area, NPK fertilizer, KCl fertilizer, herbicides, insecticides, and fungicides are not efficient while number of seeds, Urea fertilizer and manpower are inefficient.
\end{abstract}

Keywords: Rice, Farming, Efficiency, Cobb Douglass

\section{PENDAHULUAN}

Kebutuhan pangan nasional terutama beras tiap tahun akan terus meningkat bersamaan dengan bertambahnya jumlah penduduk dan berkurangnya lahan subur untuk usaha pertanian merupakan masalah dan tantangan yang berat bagi pembangunan pertanian di Indonesia. Hasil penelitian para pakar memperkirakan bahwa Indonesia akan mengalami defisit beras sebanyak 9,668 juta ton pada tahun 2020, sementara itu, untuk memenuhi peningkatan kebutuhan 
beras tersebut, menurut para akhli diperlukan penambahan areal sawah seluas 20.250 hektar per tahun (Ditjen Tanaman Pangan, 2011)

Provinsi Kalimantan Barat, memiliki agroekosistem lahan basah seluas 3.659.736 hektar (Hikmatullah E. Suparna, 2008) Sedangkan luas lahan pasang surut di Kalimantan Barat 92.250 hektar (BPS , 2017) Berdasarkan data tersebut peluang untuk pengembangan pertanian khususnya untuk tanaman padi ke lahan rawa pasang surut masih terbuka luas.

Mewujudkan pertanian berkelanjutan petani perlu memanfaatkan factor produksi secara efektif dan efisien untuk produksi usahataninya. Efisiensi produksi hendaknya penting diperhatikan oleh petani. Upaya-upaya peningkatan produksi tanaman pangan melalui jalur ekstensifikasi tampaknya semakin sulit, terbatasnya lahan pertanian produktif dan alih fungsi lahan dari pertanian ke non pertanian yang sulit dibendung karena berbagai alasan. Upaya peningkatan produksi tanaman pangan melalui efisiensi produksi menjadi salah satu pilihan yang tepat. Dengan efisiensi, petani dapat menggunakan input produksi sesuai dengan ketentuan untuk mendapat produksi yang optimal.

Desa Sungai Kakap Kecamatan Sungai Kakap Kabupaten Kubu Raya merupakan salah satu sentra terbesar produksi padi terutama di lahan rawa pasang surut dengan luapan tipe B di Kecamatan Sungai Kakap Kabupaten Kubu Raya. Sebagai salah satu sentra produksi padi, penggunaan faktor-faktor produksi input seperti lahan, benih, pupuk, pestisida, dan tenaga kerja belum efisien sehingga produktivitas padi tidak maksimal.

Berdasarkan uraian di atas maka tujuan penelitian ini adalah untuk : 1) Menganalisis pengaruh faktor produksi luas lahan, benih, tenaga kerja, pupuk, dan pestisida terhadap jumlah produksi Padi sawah di lahan rawa pasang surut Desa Sungai Kakap Kecamatan Sungai Kakap Kabupaten Kubu Raya, 2) Menganalisis efisiensi penggunaan faktor produksi usahatani Padi sawah di lahan rawa pasang surut Desa Sungai Kakap Kecamatan Sungai Kakap Kabupaten Kubu Raya.

\section{METODE PENELITIAN}

Metode yang digunakan dalam penelitian ini adalah metode survei. Lokasi penelitian ditentukan dengan sengaja (purposive) yaitu di Desa Sungai Kakap Kecamatan Sungai Kakap Kabupaten Kubu Raya. Daerah ini merupakan salah satu sentra terbesar produksi padi terutama di lahan rawa pasang surut dengan luapan tipe B di Kecamatan Sungai Kakap Kabupaten Kubu Raya, namun penggunaan faktor-faktor produksi input seperti lahan, benih, pupuk, pestisida, dan tenaga kerja belum efisien sehingga produktivitas padi tidak maksimal.

Sampel penelitian adalah sebagian atau wakil dari populasi yang diteliti (Arikunto,2006). Pada dasarnya semua anggota populasi mempunyai peluang yang sama untuk menjadi anggota sampel dalam sebuah penelitian (Hadi, 2000). Dari ukuran populasi diambil responden (sampel) secara acak. Besarnya sampel dalam penelitan ini sebanyak 35 responden sesuai dengan Rumus Solvin. Berdasarkan rumus tersebut, ukuran dari populasi sebanyak 390 petani, dari 390 petani yang menanam padi pada musim tersebut sekitar $40 \%$ nya atau sekitar 156 petani menanam padi dengan varietas Inpara 3 maka jumlah sampel dalam penelitian ini sebanyak 35 petani. Metode pengambilan sampel dilakukan secara simple random sampling dari jumlah petani padi sawah di lahan pasang surut Desa Sungai Kakap Kecamatan Sungai Kakap Kabupaten Kubu Raya yang 
menanam jenis varietas yang sama yaitu inpara 3 pada saat musim tanam gadu yaitu bulan April-Agustus 2017.

Data yang diambil dalam penelitian ini berupa data primer dan data sekunder. Data Primer diperoleh dari hasil wawancara langsung dengan responden yakni petani yang melakukan usahatani padi di lahan rawa pasang surut yang terkait dengan kegiatan usahatani padi di Kabupaten Kubu Raya yang dipandu dengan kuisioner yang berhubungan dengan penelitian. Data sekunder digunakan untuk mendukung penelitian ini antara lain: data keadaan umum lokasi penelitian, diperoleh dari beberapa instansi terkait seperti Kelurahan, Kecamatan, Balai Penyuluh Pertanian (BPP) Sungai Kakap, Dinas Pertanian Kabupaten Kubu Raya, Dinas Pertanian Propinsi Kalimantan Barat dan Kantor Badan Pusat Statistik Provinsi Kalimantan Barat. Selain itu menggunakan beberapa literatur lain yang relevan dengan penelitian, baik dari buku, hasil penelitian maupun media elektronik (internet).

Adapun variabel-variabel yang diamati dalam penelitian ini yaitu: Jumlah produksi (Y), Luas lahan (X1), Benih (X2), Pupuk Urea (X3), Pupuk NPK (X), Pupuk KCL $\left(\mathrm{X}_{5}\right)$, Herbisida $\left(\mathrm{X}_{6}\right)$, insektisida $(\mathrm{X} 7)$, Fungisida $\left(\mathrm{X}_{8}\right)$ dan Tenaga kerja $\left(\mathrm{X}_{9}\right)$.

\section{Analisis Faktor-Faktor yang Mempengaruhi Usahatani Padi}

Untuk menganalisis faktor-faktor produksi yang berpengaruh terhadap produksi padi digunakan model fungsi produksi Cobb Douglas. Fungsi CobbDouglas ditransformasikan ke dalam bentuk linier logaritma natural maka produksi usahatani padi sawah di lahan rawa pasang surut Desa Sungai Kakap Kecamatan Sungai Kakap dapat dituliskan sebagai berikut.

$$
\mathrm{LnY}=\beta 0+\beta 1 \operatorname{LnX} 1+\beta_{2} \operatorname{Ln} X_{2}+\beta 3 \operatorname{LnX} 3+\beta 4 \operatorname{LnX} 4+\ldots \ldots .+\beta 9 \operatorname{LnX} 9+\mathrm{V}
$$

Dimana:

$\mathrm{Y}=$ jumlah produksi padi yang dihasilkan dalam satu kali masa panen $(\mathrm{Kg})$

$\mathrm{X}_{1}=$ luas lahan yang digunakan dalam satu kali masa tanam $(\mathrm{Ha})$

$\mathrm{X}_{2}=$ jumlah benih yang digunakan dalam satu kali masa tanam $(\mathrm{Kg})$

$\mathrm{X} 3$ = jumlah Pupuk Urea yang digunakan dalam satu kali masa tanam diakumulasikan dalam satuan $(\mathrm{Kg})$.

X4 = jumlah Pupuk NPK yang digunakan dalam satu kali masa tanam diakumulasikan dalam satuan $(\mathrm{Kg})$.

$\mathrm{X}_{5}=$ jumlah pupuk KCL yang digunakan dalam satu kali masa tanam diakumulasikan dalam satuan $(\mathrm{Kg})$.

X6 = jumlah herbisida yang digunakan dalam satu kali masa tanam diakumulasikan dalam satuan (ltr).

$\mathrm{X} 7$ = jumlah insektisida yang digunakan dalam satu kali masa tanam diakumulasikan dalam satuan (ltr).

$\mathrm{X}_{8}=$ jumlah fungisida yang digunakan dalam satu kali masa tanam diakumulasikan dalam satuan (ltr).

X9 = jumlah tenaga kerja yang digunakan dalam satu kali masa tanam (hari orang kerja/HOK).

$\beta 0-\beta 9=$ besaran yang akan diduga

$\mathrm{V} \quad=$ kesalahan (disturbanceterm) 


\section{Analisis Efisiensi Faktor-faktor Produksi dalam Usahatani Padi}

Setelah fungsi produksi dugaan terbaik telah diperoleh maka dapat diketahui apakah faktor-faktor produksi berpengaruh secara nyata. Selanjutnya untuk mengetahui seberapa besar tingkat efisiensi dari faktor-faktor yang mempengaruhi produksi maka dilakukan perhitungan mencari Nilai Produk Marjinal (NPM), dimana Nilai Produk Marjinal (NPM) untuk suatu input sama dengan harga input $\mathrm{X}(\mathrm{Px})$, dirumuskan sebagai berikut:

$$
N P M=\frac{b . Y . P y}{X} \longrightarrow \mathrm{NPMx}=\mathrm{Px}
$$

Sehingga: $\frac{b . Y . P y}{X}=P x$ atau $\frac{b \cdot Y \cdot P y}{X . P x}=1$

Penelitian ini Y, Py, X dan Px diambil nilai rata-ratanya, sehingga dapat dituliskan persamaan sebagai berikut (Soekartawi, 2003):

Keterangan:

$$
\frac{\text { b.Y.Py }}{\mathrm{X} . \mathrm{Px}}=1
$$

$\mathrm{B}=$ Elastisitas produksi / koefisien regresi, didapat dari model regresi linier, merupakan nilai duga parameter untuk kondisi yang sebenarnya.

$\mathrm{Y}=$ Produksi rata-rata padi

Py $=$ Harga produksi rata-rata padi

$\mathrm{X}=$ Jumlah rata-rata faktor produksi padi

$\mathrm{Px}=$ Harga rata-rata faktor produksi padi

Kriteria pengambilan keputusan (Soekartawi, 2003):

1. Jika NPMx/Px $<1$, maka penggunaan faktor produksi tidak efisien.

2. Jika NPMx/Px $>1$, maka penggunaan faktor produksi belum efisien.

Jika NPMx/Px $=1$, maka penggunaan faktor produksi sudah efisien.

\section{HASIL DAN PEMBAHASAN}

\section{Analisis Faktor-faktor Produksi Usahatani Padi}

$\mathrm{R}$ square digunakan untuk mengetahui ketepatan model yang digunakan dan untuk mengukur besarnya pengaruh variabel independent terhadap variabel dependent yang dinyatakan dengan beberapa persen variasi variabel dependent yang dijelaskan oleh variabel independent yang dimasukkan dalam model regresi untuk mengetahui koefisien determinasi dapat dilihat pada tabel 1.

Tabel 1. Uji Ketepatan Model

\begin{tabular}{crrrr}
\hline Model & R & R Square & $\begin{array}{c}\text { Adjusted R } \\
\text { Square }\end{array}$ & $\begin{array}{l}\text { Std. Error of } \\
\text { the Estimate }\end{array}$ \\
\hline 1 & \multicolumn{9}{c}{$.984^{\mathrm{a}}$} & .969 & .958 & 3.18567 \\
\hline
\end{tabular}

Sumber: Analisis Data Primer 2018

Berdasarkan pada tabel 1. dapat dilihat bahwa nilai $\mathrm{R}$ sebesar $0,984^{\mathrm{a}}$ pada model penelitian dan koefisien determinasi ( $\mathrm{R}$ square) adalah sebesar 0,969 ini artinya adalah bahwa kemampuan variabel bebas dalam menjelaskan varians variabel terikat adalah sebesar $96,9 \%$. 
Uji F (Over All Test) adalah uji yang digunakan untuk mengetahui tingkat signifikan pengaruh variabel bebas (X) secara bersama-sama terhadap variabel terikat (Y) yang dapat dilihat pada tabel 2.

Tabel 2. Nilai Annova Uji F

\begin{tabular}{|c|c|c|c|c|c|c|c|}
\hline & Model & $\begin{array}{l}\text { Sum of } \\
\text { Squares }\end{array}$ & Df & $\begin{array}{l}\text { Mean } \\
\text { Square }\end{array}$ & $\mathrm{F}_{\text {hit }}$ & $F_{\text {tabel }}$ & Sig. \\
\hline \multirow[t]{3}{*}{1} & Regression & 7908.973 & 9 & 878.775 & 86.592 & 2,39 & $.000^{\mathrm{b}}$ \\
\hline & Residual & 253.713 & 25 & 10.149 & & & \\
\hline & Total & 8162.686 & 34 & & & & \\
\hline
\end{tabular}

Sumber Data : Analisis Data Primer 2018

Berdasarkan tabel 2. dapat dilihat bahwa nilai $\mathrm{F}$ hitung yaitu sebesar 86,592 sedangkan $\mathrm{F}$ tabel dapat diperoleh dengan menggunakan Tabel $\mathrm{F}$ dengan derajat kebebasan (Dk) Residual (Sisa) yaitu 20 sebagai Dk penyebut dan Dk Regression (Perlakuan) yaitu 9 sebagai Dk pembilang dengan taraf signifikan (0.05) sehingga di peroleh nilai $\mathrm{F}$ tabel yaitu 2,39 maka $\mathrm{F}$ hitung 86,592 $>2,16 \mathrm{~F}$ tabel. Nilai $\mathrm{F}$ hitung $>$ nilai $\mathrm{F}$ tabel maka $\mathrm{Ha}$ di terima dan Ho di tolak yang artinya adalah bahwa variabel indevendent berpengaruh signifikan terhadap variabel devendent atau variabel $\mathrm{X}$ berpengaruh signifikan terhadap produksi usahatani padi (Y).

2. Analisis Fungsi Produksi Usahatani padi

Fungsi produksi yang digunakan untuk menganalisis Usahatani padi pada penelitian ini adalah dengan menggunakan fungsi produksi Cobb-Douglass, yaitu dengan melibatkan dua atau lebih variabel yang disebut dengan analisis regresi berganda, dimana yang satu disebut variabel dependen (Y) dan yang lain disebut variabel independen (X). Variabel independen meliputi: Luas Lahan (Ha), Jumlah Benih (Kg), Pupuk Urea (Kg), Pupuk NPK (Kg), Pupuk KCL/KNO3 (Kg), Herbisida (L), Insektisida (L), Fungisida (L), Tenaga Kerja (Hok),

Pengaruh masing-masing variabel faktor produksi $(\mathrm{X})$ terhadap tingkat produksi (Y) dapat dilihat dengan membandingkan nilai signifikansi dengan derajat kepercayaan 5\% atau sebesar $(0,05)$. Hasil analalisis signifikansi pada padi dapat dilihat pada tabel 3. berikut.

Tabel 3. Koefisien Regresi Fungsi Produksi Padi

\begin{tabular}{|c|c|c|c|c|c|}
\hline \multirow{2}{*}{ Model } & \multicolumn{2}{|c|}{$\begin{array}{l}\text { Unstandardized } \\
\text { Coefficients }\end{array}$} & \multirow{2}{*}{$\begin{array}{c}\text { Standardized } \\
\text { Coefficients }\end{array}$} & \multirow[t]{2}{*}{$\mathrm{t}$} & \multirow[t]{2}{*}{ Sig. } \\
\hline & B & Std. Error & & & \\
\hline Luas Lahan (ha) & .275 & .129 & .227 & 2.126 & .044 \\
\hline Jumlah Benih (kg) & .113 & .093 & .076 & 1.216 & .235 \\
\hline Pupuk Urea (kg) & -.063 & .079 & -.087 & -.801 & .431 \\
\hline Pupuk NPK (kg) & .121 & .056 & .177 & 2.182 & .039 \\
\hline Pupuk KCL (kg) & .157 & .063 & .240 & 2.482 & .020 \\
\hline Herbisida (l) & .201 & .089 & .201 & 2.268 & .032 \\
\hline Insektisida (1) & .087 & .064 & .114 & 1.348 & .190 \\
\hline Fungisida (l) & .104 & .057 & .110 & 1.810 & .082 \\
\hline Tenaga Kerja (HOK) & .045 & .113 & .035 & .400 & .692 \\
\hline
\end{tabular}

Sumber: Analisis Data Primer, 2018 
Tabel 3. menunjukkan Nilai Produk Marginal (NPM) dari faktor produksi yang digunakan pada usahatani padi sawah di lahan rawa pasang surut desa Sungai Kakap Kecamatan Sungai Kakap,

Hasil analisis faktor-faktor produksi usahatani padi menunjukan bahwa faktor produksi luas lahan, pupuk NPK, pupuk KCL, dan Herbisida berpengaruh nyata terhadap produksi padi.

3. Analisis Efisiensi Penggunaan Faktor-faktor Produksi Usahatani Padi

Tabel 4. Analisis Efisiensi Faktor Produksi Usahatani Padi

\begin{tabular}{|c|c|c|c|c|c|c|c|c|}
\hline $\begin{array}{c}\text { Faktor } \\
\text { Produksi }\end{array}$ & B & $\begin{array}{c}\text { Produksi } \\
\text { Rata-rata } \\
\text { Y }\end{array}$ & $\begin{array}{c}\text { Faktor } \\
\text { Produksi } \\
\text { X }\end{array}$ & $\begin{array}{c}\text { Harga } \\
\text { produksi } \\
\text { Py }\end{array}$ & $\begin{array}{l}\text { Harga } \\
\text { Faktor } \\
\text { produksi } \\
\text { Px }\end{array}$ & NPM & $\begin{array}{l}\text { NPM/ } \\
\text { Px }\end{array}$ & Ket. \\
\hline $\begin{array}{l}\text { Luas } \\
\text { Lahan }\end{array}$ & 0,275 & 2.354 & 0,73 & 4.834 & $\begin{array}{r}3.000 .00 \\
0\end{array}$ & $\begin{array}{r}4.292 .0 \\
16\end{array}$ & 1,43 & $\begin{array}{l}\text { Belum } \\
\text { Efisien }\end{array}$ \\
\hline $\begin{array}{l}\text { Jumlah } \\
\text { Benih }\end{array}$ & 0,113 & 2.354 & 24,00 & 4.834 & 5.509 & 53.621 & 9,73 & $\begin{array}{l}\text { Belum } \\
\text { Efisien }\end{array}$ \\
\hline $\begin{array}{l}\text { Pupuk } \\
\text { Urea }\end{array}$ & $-0,063$ & 2.354 & 96,29 & 4.834 & 2.131 & -7.495 & $-3,52$ & $\begin{array}{c}\text { Tidak } \\
\text { Efisien }\end{array}$ \\
\hline $\begin{array}{l}\text { Pupuk } \\
\text { NPK }\end{array}$ & 0,121 & 2.354 & 104,43 & 4.834 & 2.480 & 13.238 & 5,34 & $\begin{array}{l}\text { Belum } \\
\text { Efisien }\end{array}$ \\
\hline $\begin{array}{l}\text { Pupuk } \\
\text { KCL }\end{array}$ & 0,157 & 2.354 & 47,86 & 4.834 & 6.500 & 37.279 & 5,74 & $\begin{array}{l}\text { Belum } \\
\text { Efisien }\end{array}$ \\
\hline Herbisida & 0,201 & 2.354 & 2,58 & 4.834 & 68.714 & 888.201 & 12,93 & $\begin{array}{l}\text { Belum } \\
\text { Efisien }\end{array}$ \\
\hline $\begin{array}{l}\text { Insektisid } \\
\mathrm{a}\end{array}$ & 0,087 & 2.354 & 1,34 & 4.834 & 60.000 & 737.514 & 1,29 & $\begin{array}{l}\text { Belum } \\
\text { Efisien }\end{array}$ \\
\hline Fungisida & 0,104 & 2.354 & 0,42 & 4.834 & 175.000 & $\begin{array}{r}2.833 .4 \\
57\end{array}$ & 16,19 & $\begin{array}{l}\text { Belum } \\
\text { Efisien }\end{array}$ \\
\hline $\begin{array}{l}\text { Tenaga } \\
\text { Kerja }\end{array}$ & 0,045 & 2.354 & 68,19 & 4.834 & 70.000 & 7.551 & 0,11 & $\begin{array}{r}\text { Tidak } \\
\text { Efisien } \\
\end{array}$ \\
\hline
\end{tabular}

Sumber: Analisis Data Primer 2018

Tabel 4. menunjukkan Nilai Produk Marginal (NPM) dari faktor produksi yang digunakan pada usahatani padi sawah di lahan rawa pasang surut desa Sungai Kakap Kecamatan Sungai Kakap, tidak terdapat satupun faktor produksi yang sudah menunjukkan tingkat efisien. Penggunaan faktor produksi luas lahan, jumlah benih,pupuk NPK, pupuk KCL, Herbisida, Insektisida dan Fungisidaantara NPM dan harga masing-masing faktor produksi $>1$ yang berarti bahwa faktor produksi tersebut belum efisien. Sedangkan pupuk urea dan tenaga kerja antara NPM dan harga masing-masing faktor produksi $<1$ yang berarti bahwa faktor produksi tersebut tidak efisien.

Hasil analisis faktor-faktor produksi usahatani padi menunjukan bahwa faktor produksi luas lahan, pupuk NPK, pupuk KCL, Herbisida dan berpengaruh nyata terhadap produksi padi. Sehingga, untuk pembahasan efisiensi penggunaan faktor-faktor produksi Usahatani padi, hanya untuk kelima faktor produksi tersebut yaitu sebagai berikut. 


\section{a. Faktor Produksi Luas Lahan}

Nilai Produk Marjinal (NPM) dari faktor produksi luas lahan apabila dibandingkan dengan sewa lahan tersebut (Px1) yaitu sebesar 1,51 atau lebih dari satu (NPM/Px1>1) sehingga penggunaan faktor produksi luas lahan ini belum efisien. Efisiensi dapat dicapai dengan menambah satu satuan luas lahan sehingga NPM luas lahan sama dengan harga luas lahan tersebut.

Pada tabel 4.11 diketahui bahwa elastisitas luas lahan terhadap produksi padi sebesar 0,290 rata-rata luas lahan yang digunakan oleh para petani padi yaitu $0,73 \mathrm{Ha}$, rata-rata produksi padi selama 1 masa produksi $2.354 \mathrm{~kg} / \mathrm{MT}$, sewa lahan Rp 3.000.000 per hektar dan hargapadi per kg Rp 4.834 per kilogram. Belum tercapainya kondisi optimal pada penggunaan faktor produksi luas lahan dikarenakan sebagian besar petani di Desa Sungai Kakap menggunakan lahan milik sendiri yang relatif sempit. Kendala modal menjadi salah satu alasan petani, karena sewa lahan yang relatif mahal yaitu sekitar Rp 3.000.000 per hektar. Selain itu juga dengan bertambahnya luas lahan jumlah faktor produksi yang lain juga bertambah sehingga petani perlu modal yang cukup besar ini dikarenakan sebagian besar petani padi memiliki modal yang relatif kecil.

\section{b. Faktor Produksi Pupuk NPK}

Nilai Produk Marjinal (NPM) dari faktor produksi pupuk NPK apabila dibandingkan dengan harga pupuk NPK tersebut (Px4) yaitu sebesar 5,34 atau lebih dari satu (NPM/Px4>1) sehingga penggunaan faktor produksi pupuk NPK ini belum efisien. Efisiensi dapat dicapai dengan menambah satu satuan pupuk NPK sehingga NPM pupuk NPK sama dengan harga pupuk NPKtersebut.

Hasil penelitian menunjukkan rata-rata pupuk NPK yang digunakan selama 1 musim tanam 104,43kg/MT dengan luasan 0,73 ha atau sekitar 143 $\mathrm{kg} / \mathrm{MT} / \mathrm{ha}$, rata-rata produksi padi selama musim tanam $2.354 \mathrm{~kg} / \mathrm{MT}$, harga pupuk NPK Rp 2.480 per kilogram dan harga padi Rp 4.834 per kilogram. Penggunaan faktor produksi pupuk NPK masih kurang dari yang dianjurkan yaitu 200 kg/ha (Dinas Pertanian Kabupaten Kubu Raya, 2018), sehingga untuk meningkatkan produksi perlu penambahan penggunan pupuk NPK. Masih belum efisiennya penggunaan pupuk NPK ini dikarenakan masih minimnya informasi penggunaan pupuk NPK yang tepat oleh petani, petani menggunakan pupuk NPK hanya berdasarkan pengalaman dan kebiasaan petani ini sesuai dengaan penelitian yang dilakukan (Mistaruan 2014).

\section{c. Faktor Produksi Pupuk KCL}

Nilai Produk Marjinal (NPM) dari faktor produksi pupuk KCL apabila dibandingkan dengan pupuk KCL tersebut (Px5) yaitu sebesar 5,74 atau lebih dari satu (NPM/Px5> 1) sehingga penggunaan faktor produksi pupuk KCL inibelum efisien. Efisiensi dapat dicapai dengan menambah satu satuan pupuk KCLsehingga NPM pupuk KCLsama dengan harga pupuk KCLtersebut.

Pada tabel 4.11 diketahui bahwa elastisitas pupuk KCLterhadap produksi padi sebesar 0,13 rata-rata pupuk KCLyang digunakan oleh para petani padi yaitu $47,86 \mathrm{Kg} / \mathrm{Mt}$ atau sekitar $65,56 \mathrm{~kg} / \mathrm{ha}$, rata-rata produksi padi selama 1 tahun produksi $2.354 \mathrm{~kg} / \mathrm{MT}$, harga pupuk KCL Rp 6.500 per kg dan harga padi per $\mathrm{kg}$ Rp 4.834 per kilogram. Belum tercapainya kondisi optimal pada penggunaan faktor produksi pupuk KCL dikarenakan sebagian besar petani di Desa Sungai Kakap menggunakan pupuk KCL masih berdasarkan kebiasaan dan pengalaman petani. Petani seharusnya menambah penggunaan pupuk KCL agar menjadi 
efisien ini sejalan dengan rekomendasi oleh (Balai Penelitian dan Pengembangan Pertanian, 2016) dan (Dinas Pertanian Kabupaten Kubu Raya, 2018) bahwa penggunaan pupuk KCLyaitu sebesar $100 \mathrm{~kg} / \mathrm{ha}$ atau sekitar $70-80 \mathrm{~kg} / \mathrm{MT}$ untuk luasan lahan 0,73 ha.

\section{d. Faktor Produksi Herbisida}

Nilai Produk Marjinal (NPM) dari faktor produksi herbisida apabila dibandingkan dengan herbisidatersebut (Px6) yaitu sebesar 12,93 atau lebih dari satu (NPM/Px6> 1) sehingga penggunaan faktor produksi herbisidaini belum efisien. Efisiensi dapat dicapai dengan menambah satu satuan herbisidasehingga NPM herbisidasama dengan harga herbisidatersebut.

Pada tabel 4.11 diketahui bahwa elastisitas herbisidaterhadap produksi padi sebesar 0,293 rata-rata herbisidayang digunakan oleh para petani padi yaitu 2,58 1/Mt, rata-rata produksi padi selama 1 musim produksi $2.354 \mathrm{Kg} / \mathrm{Mt}$, harga herbisida Rp 68.174 per liter dan hargapadi per kg Rp 4.834 per kilogram. Belum tercapainya kondisi optimal pada penggunaan faktor produksi herbisida dikarenakan sebagian besar petani di desa Sungai Kakap menggunakan herbisida masih berdasarkan kebiasaan dan pengalaman petani. Penggunaanherbisida yang dilakukan petani seharusnya ditambah agar penggunaan herbisida menjadi efisien. (Dinas Pertanian Kabupaten Kubu Raya, 2018) anjuran penggunaan herbisida sekitar 5 1/Ha.

\section{KESIMPULAN DAN SARAN Kesimpulan}

Berdasarkan hasil penelitian dan pembahasan yang telah dilakukan, maka ditarik kesimpulan bahwa:

1. Penggunaan faktor produksi usahatani padi sawah dilahan rawa pasang surut di Desa Sungai Kakap Kecamatan Sungai Kakap Kabupaten Kubu Raya yaitu luas lahan, benih, pupuk urea, pupuk NPK, pupuk KCL, Herbisida, Insektisida, Fungisida dan tenaga kerja secara simultan berpengaruh secara nyata terhadap produksi. Secara parsial faktor produksi luas lahan, pupuk NPK, pupuk KCL, Herbisida dan Tenaga kerja berpengaruh secara nyata terhadap produksi usahatani padi sawah di lahan rawa pasang surut sedangkan jumlah benih, pupuk urea, insektisida dan fungisida secara parsial tidak berpengaruh nyata terhadap produksi usahatani padi sawah di lahan rawa pasang surut.

2. Penggunaan faktor-faktor produksi usahatani padi sawah di lahan rawa pasang surut Desa Sungai Kakap Kecamatan Sungai Kakap Kabupaten Kubu Raya berupa luas lahan, pupuk NPK, pupuk KCL, herbisida, insektisida dan fungisida belum efisien, sedangkan pupuk urea dan tenaga kerja penggunaanya tidak efisien.

\section{Implikasi Kebijakan}

Setelah dilakukan analisis efisiensi faktor-faktor produksi usahatani padi sawah di lahan rawa pasang surut Desa Sungai Kakap Kecamatan Sungai Kakap Kabupaten Kubu Raya maka saran yang dapat diberikan penulis yaitu:

1. Untuk meningkatkan produksi padi dapat dilakukan dengan cara menambah faktor Luas lahan, pupuk NPK, pupuk KCL, Herbisida dan tenaga kerja sampai pada tingkat efisien, sedangkan penggunaan faktor produksi benih, 
pupuk urea dan tenaga kerja perlu dikurangi karena penggunaanya tidak efisien.

2. Pemerintah maupun lembaga non pemerintah lainnya agar bisa memberikan bantuan baik berupa bantuan langsung berupa faktor-faktor produksi maupun inovasi-inovasi terbaru yang bisa digunakan oleh petani.

\section{DAFTAR PUSTAKA}

Arikunto, Suharsimi. 2006. Prosedur Penelitian : Suatu pendekatan Praktek. Rineka Cipta. Jakarta.

Ari Sudarman. 1991. Teori Ekonomi Mikro. BPFE. Yogyakarta.

BPP Kecamatan Sungai Kakap. 2014. Monografi Wilayah Balai Penyuluhan Kecamatan Sungai Kakap Kabupaten Kubu Raya. BPP Kecamatan Sungai Kakap. Kubu Raya.

BPS. 2017. Kalimantan Barat Dalam Angka Tahun 2016. BPS Provinsi Kalimantan Barat. Pontianak.

Dinas Pertanian Tanaman Pangan dan Hortikultura Provinsi Kalimantan Barat. 2017. Luas Baku Lahan Sawah di Kalimantan Barat. Dinas Pertanian Tanaman Pangan dan Hortikultura Provinsi Kalimantan Barat. Pontianak.

Dinas Pertanian Kabupaten Kubu Raya. (2018). Standar Operational Prosedur Bididaya Padi . Pontianak: Dinas Pertanian Kabupaten Kubu Raya.

Hikmatullah E. Suparna, D. Subardja. 2008. Pola Kebijakan Pemanfaatan Sumberdaya Lahan Basah Rawa dan Pantai.

Muhyidin. 2010. Efisiensi Penggunaan Faktor-faktor Produksi Pada Uasahatani Padi di Kecamatan Pekalongan Selatan. Universitas Sebelas Maret. Surakarta. 